\title{
Lipase immobilized on functionalized superparamagnetic few-layer graphene oxide as an efficient nanobiocatalyst for biodiesel production from chlorella vulgarise bio-oil
}

\author{
Tahereh Nematian \\ University of Tehran \\ Alireza Shakeri \\ University of Tehran \\ Zeinab Salehi ( $\nabla$ zsalehy@ut.ac.ir) \\ University of Tehran \\ Ali Aakbar Saboury \\ University of Tehran
}

\section{Research}

Keywords: Few-layer graphene oxide; Biodiesel; Chlorella vulgaris; Bio-oil; Superparamagnetic; Nanobiocatalyst.

Posted Date: December 9th, 2019

DOI: https://doi.org/10.21203/rs.2.18470/v1

License: (c) (1) This work is licensed under a Creative Commons Attribution 4.0 International License.

Read Full License 


\section{Abstract}

Background Microalgae, due to its well-recognized advantages have been gained renewed interest as potentially good feedstock for biodiesel. Production of fatty acid methyl esters (FAMEs) as a type of biodiesel was carried out from Chlorella vulgaris bio oil. Biodiesel was produced in the presence of nanobiocatalysts composed of immobilized lipase on functionalized superparamagnetic few-layer graphene oxide via a transesterification reaction. A hybrid of few-layer graphene oxide and Fe304 (MGO) was prepared and characterized. The MGO was functionalized with 3-aminopropyl triethoxysilane (MGO-AP) as well as with a couple of AP and glutaraldehyde (MGO-AP-GA). The Rhizopus oryzae lipase (ROL) was immobilized on MGO and MGO-AP using electrostatic interactions as well as on MGO-AP-GA using covalent bonding. The supports, MGO, MGO-AP, and MGO-AP-GA, as well as Nano-biocatalyst, ROL/MGO, ROL/MGO-AP, and ROL/MGO-AP-GA, were characterized using FESEM, VSM, FTIR, and XRD. The fewlayer graphene oxide was characterized using AFM and the surface charge of supports was evaluated with the zeta potential technique. The nano-biocatalysts assay was performed with an evaluation of kinetic parameters, loading capacity, relative activity, time-course thermal stability, and storage stability. Biodiesel production was carried out in the presence of nano-biocatalysts and their reusability was evaluated in 5 cycles of transesterification reaction. Results: The AFM analysis confirmed the few-layer structure of graphene oxide and VSM also confirmed that all supports were superparamagnetic. The maximum loading of ROL (70.2\%) was related to MGO-AP-GA. The highest biodiesel conversion of $71.19 \%$ achieved in the presence of ROL/MGO-AP-GA. Furthermore, this nano-biocatalyst could maintain $58.77 \%$ of its catalytic performance after 5 cycles of the transesterification reaction and was the best catalyst in the case of reusability. Conclusions: In this study, the synthesized nano-biocatalyst based on bare and functionalized magnetic graphene oxide was applied and optimized in the process of converting microalgae bio-oil to biodiesel for the first time and compared with bare lipase immobilized on magnetic nanoparticles. Results showed that the loading capacity, kinetic parameters, thermal stability, and storage stability improved by the functionalization of MGO. The biocatalysts, which were prepared via covalent bonding immobilization of enzyme generally, showed better characteristics. Keywords Few-layer graphene oxide; Biodiesel; Chlorella vulgaris; Bio-oil; Superparamagnetic; Nano-biocatalyst.

\section{Background}

The increasing dependency of the world to petroleum concurrent with the reduction in fossil fuel resources and environmental pollution have persuaded the governments to develop renewable alternatives ${ }^{1,2}$. The biofuels are of these alternatives which can be used for transportation instead of petroleum-based fuels. They are produced from biosources such as biomass through various processes. The light alcohols and ethers (methanol, ethanol, and diethyl ether), aliphatic and aromatic hydrocarbons, and fatty acid methyl esters can be produced from biomasses 3,4 . Actually, the carbon content of theses fuels, which is combusted in the engines and released into the atmosphere, has been stabilized from the atmosphere in the masses of the plants. So, the biofuels have zero net carbon release into the environment ${ }^{5,6}$. 
Biodiesel is a diesel fuel produced from bioresources. Fatty acid methyl esters (FAMEs) and other monoalkyl esters of long-chain fatty acids are well-known types of biodiesel. It has been reported that the addition of biodiesel to petroleum diesel can increase the cetane number of fuel and improve the lubrication of engine ${ }^{7}$. The plant oil and animal fat can be converted to this type of fuel through a transesterification reaction. Microalgae because of high oil production efficiency and rapid growth rate and growing ability in the wastewater or non-arable lands has been highly regarded as affordable and economical feedstock for biodiesel production ${ }^{8-10}$. Among algal species, Chlorella vulgaris, due to its lipid-rich biomass content and easy cultivation has great potential as a feedstock for biodiesel production 11-13.

The transesterification reaction for the purpose of biodiesel production is performed using biomass oily content and methanol/ethanol in the presence of catalysts. Catalysts used in this reaction are classified into acidic, basic, and enzymatic ${ }^{14,15}$. Enzymatic catalysts have been widely used in different industrial applications because of selective performance and easy product separation. Lipases are well-known enzymes used as biocatalysts for the hydrolysis and transesterification of triglycerides ${ }^{16-18}$. The immobilization increases the chemical and thermal stability of the enzyme and can improve its catalytic activity. Furthermore, the enzyme immobilization facilitates catalyst separation at the end of the reaction. The covalent bonding, electrostatic adsorption, encapsulation, and entrapping are common methods for enzyme immobilization ${ }^{19-21}$.

Different nanostructure materials have been used as support for the immobilization of enzymes. A variety of nanostructures such as nanoparticles, polymer nanofibers and nanocomposites, nano and mesoporous silica, carbon nanotubes, graphene, and graphene oxide have been used for enzyme immobilization ${ }^{22-25}$. The carbon-based supports have been extensively applied for this aim because of neutral and biodegradable nature, and thermal and chemical stability. The relatively easy functionalization of these structures makes them very suitable for electrostatic adsorption and covalent binding of the enzyme to the support ${ }^{26-28}$. Recently, graphene oxide (GO) has been used in many applications because of its unique properties. The large surface area, high enzyme loading efficiency, thermal stability, having different functional groups, and the modifiability, make GO a very interesting carbon nanomaterial for enzyme immobilization 29,30 .

Recent research has been devoted to the investigation of thermostability and capacity of enzyme loading on graphene oxide. The immobilization of Brevibacillus borstelensis lipase on functionalized GO with glutaraldehyde showed a positive and remarkable effect on the thermostability of biocatalyst at $95^{\circ} \mathrm{C}$ over a broad alkaline $\mathrm{pH}$ range of 7 to $12^{31}$. Modified exfoliated graphene oxide via 3-aminopropyl triethoxysilane (AP) has been employed as support for Candida rugosa lipase immobilization and used for the synthesis of ester ethyl caprylate. The results showed an improvement in the thermal stability of biocatalyst so that at $40{ }^{\circ} \mathrm{C}$, enzyme activity has reached $80 \%$ for immobilized lipase and $58 \%$ for free one ${ }^{32}$. 
The magnetically recoverable catalysts have been developed for various reactions. The magnetization of catalyst facilitates its separation using an external magnetic field upon the reaction termination. This method has improved the reusability of catalysts and biocatalysts ${ }^{33,34}$. The immobilization of enzymes on bare and functionalized $\mathrm{Fe}_{3} \mathrm{O}_{4}$ superparamagnetic nanoparticles (MNPs) and MNPs-carbon supports have been investigated. The MNPs-GO hybrid has been used as a sensor, catalyst, and adsorbent for the removal of arsenic, antibiotics, and some other water pollutants ${ }^{35-38}$. The lipase immobilization on magnetic amino-functionalized $\mathrm{GO}$ for the aim of biodiesel production from $R$. communis oil has been performed. It has been reported that the immobilization increases the biodiesel up to $78 \%$ compared with free lipase ${ }^{39}$. The similar support has been used for the immobilization of Candida rugosa lipase for the conversion of soybean oil to biodiesel. The biodiesel production yield of $92.8 \%$ and 5 times recyclability of the catalyst has been reported 40 .

In this research, superparamagnetic nano-biocatalysts consist of electrostatically and covalently immobilized Rhizopus oryzae lipase on MNP and magnetized graphene oxide were synthesized and characterized. The loading capacity, kinetic parameters, thermal and storage stability of these catalysts were evaluated in a model hydrolysis reaction. The biodiesel production from transesterification of Chlorella vulgaris microalgae bio-oil was carried out in the presence of these nano-biocatalysts and also the catalyst reusability was investigated.

\section{Results And Discussion}

\section{Characterization}

\section{Atomic force microscopy (AFM)}

Atomic force microscopy (AFM) height profile of the spin-coated sample on the silicon oxide substrate was shown in figure 2. The profile revealed a successful exfoliation of graphite layers and demonstrated the few-layer graphene oxide structure. Therefore, the results confirm the synthesis of nanoscale fewlayer graphene oxide. As shown in the graph, the thickness of the GO pieces is approximately $2.5 \mathrm{~nm}$. Considering that the thickness of every layer in the graphite structure is $0.8 \mathrm{~nm}$, the achieved GO pieces have almost three layers of carbon sheets ${ }^{41}$.

\section{FTIR spectra}

Figure 3 shows the FT-IR spectra of a) MNP, b) GO, and c) MGO. For the bare MNP (Figure 3a), two dominant peaks were appeared at $567 \mathrm{~cm}^{-1}$ and $3400 \mathrm{~cm}^{-1}$ which are related to $\mathrm{Fe}-\mathrm{O}$ and $\mathrm{O}-\mathrm{H}$ bonds, respectively. In the $\mathrm{GO}$ spectrum (Figure $3 \mathrm{~b}$ ), the broad peak around $3400 \mathrm{~cm}^{-1}$ is attributed to $\mathrm{O}-\mathrm{H}$ stretching vibration indicating the presence of $\mathrm{O}-\mathrm{H}$ and $\mathrm{COOH}$ functional groups in the $\mathrm{GO}$ structure. The presence of oxygen-containing functional groups, such as $\mathrm{C}=\mathrm{O}$ stretching vibration of carboxylic and carbonyl groups, $\mathrm{C}-\mathrm{O}$ stretching vibration of an epoxy group and $\mathrm{C}-\mathrm{OH}$ group was demonstrated with the peaks appeared at 1732,1252 and $1040 \mathrm{~cm}^{-1}$, respectively. Furthermore, the presence of $\mathrm{C}=\mathrm{C}$ bonds in 
aromatic rings on GO plates was demonstrated with the peak appeared at $1611 \mathrm{~cm}^{-1} 42$. The spectrum of MGO showed a peak that appeared at $574 \mathrm{~cm}^{-1}$. It is related to the $\mathrm{Fe}-\mathrm{O}$ bond and can be detected in all the magnetic nanostructures spectrums (Figures 3 and 4 ).

Figure 4 shows the FTIR spectra of a) MGO-AP, b) MGO-AP-GA, c) ROL, and d) ROL/ MGO-AP-GA. In the first functionalization step of MGO (Figure 4a), the appearance of peaks at 1094 and $1034 \mathrm{~cm}^{-1}$ are related to $\mathrm{Si}-\mathrm{O}-\mathrm{C}$ and $\mathrm{Si}-\mathrm{O}-\mathrm{Si}$ bonds and confirmed the functionalization of MGO with amine groups. The bonds in the range of $2850-2920 \mathrm{~cm}^{-1}$ ascribed to $\mathrm{CH}_{2}$, provide another evidence of AP attachment 43. In the MGO-AP-GA spectrum (Figure 4b), enhancement of absorption peaks at $1635 \mathrm{~cm}^{-1}$ can be related to the $\mathrm{N}=\mathrm{C}$ covalent bond formation between glutaraldehyde and AP. Also, the peak at $1740 \mathrm{~cm}^{-1}$ can be related to $\mathrm{C}=0$ aldehyde groups of glutaraldehyde. The FTIR spectrum of ROL (Figure $4 \mathrm{~d}$ ) indicated two characteristic peaks in the wavenumbers of $1610 \mathrm{~cm}^{-1}$ and $1454 \mathrm{~cm}^{-1}$. The peak at 1610 $\mathrm{cm}^{-1}$ associated with the $\mathrm{C}=\mathrm{O}$ stretching vibration in amide-type I and $1454 \mathrm{~cm}^{-1}$ associated with the N-H bending and $\mathrm{C}-\mathrm{N}$ stretching vibrations in amide-type II ${ }^{44}$. The related peaks of amide-type I and amidetype II are attributed to the protein backbone of the enzyme. Broadening and increasing intensity of the characteristic absorption peaks of ROL in the FTIR spectrum of ROL/MGO-AP-GA (Figure 4d) confirmed successful immobilization of ROL on MGO-AP-GA ${ }^{45}$.

\section{XRD patterns}

Typical XRD patterns for synthesized supports are presented in figures 5 and 6 . The existence of six characteristic peaks at $2 \theta$ of $30.0^{\circ}, 35.4^{\circ}, 43.1^{\circ}, 53.5^{\circ}, 57.0^{\circ}$, and $62.6^{\circ}$ in the spectrum of MNP (Figure $5 a$ ) indicated the formation of the crystalline structure of MNP. The XRD pattern of GO in figure $5 b$ showed a strong and sharp peak at $2 \theta=10.74^{\circ}$, which is related to the exfoliated GO with a d-spacing of $0.84 \mathrm{~nm}^{46}$. All diffraction peaks in the XRD pattern of MGO (Figure $5 \mathrm{c}$ ) are related to the MNP crystalline phase. The characteristic peak of $\mathrm{GO}$ was broadened and weakened due to the exfoliation of $\mathrm{GO}$ during the MGO synthesis process. As shown in figure 6, the appeared peaks in XRD patterns of MGO-AP, MGO-AP-GA, and ROL/MGO-AP-GA are similar to the MGO peaks which means that functionalization and immobilization process has no effect on the crystallinity of MGO.

\section{FESEM micrographs}

The FESEM was employed to characterize the morphology of the prepared MNP, GO and MGO. Also, the FESEM and EDS elemental mapping were used for evaluation of morphology and elemental distribution on ROL/MGO-AP-GA, as the nano-bio catalyst with the best performance (Figure 7). As shown in figure $7 \mathrm{a}$, the spherical shape of MNP is obvious and the particle size is in range of 20-30 nm. The smooth and sheets-like structure of $\mathrm{GO}$ can be observed in figure 7b. Figure 7c shows the FESEM micrograph of MGO. The created wrinkles and the spherical-shape MNP nanoparticles are clearly obvious on the surface of GO. Furthermore, the size range of MNP on the GO sheets is relatively as same as the bare MNP. Figure 7d illustrates the FESEM micrograph of ROL/MGO-AP-GA. The brighter fine zones that are visible on the 
surface of MGO in FESEM micrograph can be related to ROL immobilization on MGO-AP-GA. The EDS elemental mapping of ROL/MGO-AP-GA shows a good distribution of elements on the nano-bio catalyst (Figure 7c).

\section{Vibrating sample magnetometer (VSM)}

Vibrating sample magnetometer (VSM) analysis was used for the evaluation of magnetic properties of synthesized supports. As shown in figure 8, the magnetic hysteresis loop for all curves was S-like shape over the applied magnetic field at room temperature, indicating that the samples were superparamagnetic. The magnetic response of MNP, MGO, MGO-AP, and MGO-AP-GA were 63.67, 23.19, 17.56 and 16.06 emu. $\mathrm{g}^{-1}$, respectively. Depletion in saturation magnetization $\left(M_{\mathrm{s}}\right)$ of MGO compare with the bare MNP can be attributed to the relatively low MNP mass ratio in the MGO hybrid. The hybrid magnetization changes with the different MNP to GO mass ratios. After AP and GA grafting on MGO, the $M_{s}$ value was decreased due to the introduction of non-magnetic components to the magnetic one.

\section{Zeta potential measurement}

The zeta potential measurement was carried out in phosphate buffer medium (100 mM, pH 7.5) to evaluate the surface charge of synthesized supports. As shown in Table 1, the zeta potential of MGO was -33.58 which more negative than of MNP. The more negative charge of MGO than MNP is related to hydroxyl and carboxyl groups on MGO surface. After the modification of MGO with AP, a slight increase of zeta potential was observed. It can be related to this fact that amine groups contain less negative charge than hydroxyl and carboxyl groups ${ }^{47}$. The zeta potential of the MGO-AP-GA decreased to -20.24 when the GA was added to the MGO-AP.

\section{Nano-biocatalysts assay}

\section{Loading capacity}

The loading capacity of immobilized ROL on the supports was evaluated using Bradford's method and results were reported in figure 9 . For this purpose, the supports were exposed to enzyme solutions with different ROL initial concentrations. As shown in figure 9a, loading capacity increased with increasing of initial ROL concentration and then reached a maximum value for each support. However, the enzyme loading showed no significant increase for the solutions with concentrations upper than $21 \mathrm{mg} \cdot \mathrm{mL}^{-1}$ and $14 \mathrm{mg} \cdot \mathrm{mL}^{-1}$ for MGO-based supports and bare MNP, respectively. Saturation of supports because of their limited capacity is the reason of this observation ${ }^{48}$. The optimum loading percentage of ROL on the supports was varied from $24.23 \pm 0.55$ to $70.20 \pm 0.69 \mathrm{wt}$.\% (Figure 9b). The MGO-AP-GA showed the highest ROL loading capacity and the lowest was attributed to MNP. It can be related to the lower surface area of MNP compared with MGO-based supports. Also, the functionalization of MGO with AP and GA increased loading capacity due to creating a wider spherical area for enzyme attachment.

\section{Relative activity}


Figure 10 shows the effect of the ROL initial concentration on the relative activity of nano-biocatalysts. The prepared nano-biocatalysts in the process of loading capacity tests were used for relative activity evaluation. The relative activity was defined as the ratio of each sample activity to its maximum activity 49 . The increasing of initial ROL concentration caused relative activity enhancement up to the maximum value (100\%). The more loaded enzyme and subsequently, more enzyme-substrate contacts in the reaction increased the relative activity. In the case of MNP, when the ROL initial concentration was 14.78 $\mathrm{mg} \cdot \mathrm{mL}^{-1}$, the loading capacity and relative activity were maximum. For MGO-based nano-biocatalysts, the highest relative activity was obtained for ROL initial concentration of $10.61 \mathrm{mg} \cdot \mathrm{mL}^{-1}$ and was not equal to the maximum loading capacity. More increasing in ROL initial concentration causes the accumulation of enzyme molecules on supports surface. Therefore, the substrate accessibility to enzymes is limited and the relative activity decreases ${ }^{48}$.

\section{Kinetic parameter}

The Michaelis-Menten kinetic parameters for the hydrolysis of $p$-PNP in the presence of free and immobilized ROL were measured and presented in table 2 . The $\mathrm{K}_{\mathrm{m}}$ is the substrate concentration in which the reaction rate is at half of its maximum velocity and shows an affinity of attachment between enzyme and substrate. The ROL immobilization on the supports caused an obvious reduction in $\mathrm{K}_{\mathrm{m}}$ value which indicating more enzyme-substrate affinity of attachment. The $\mathrm{K}_{\mathrm{m}}$ was decreased by more than 4 -fold after attachment of AP and GA to MGO. The less negative $\zeta$ potential of MGO-AP than MGO which is due to the existence of amine groups in AP structure, as well as the increasing of surface hydrophilicity due to the GA attachment can be responsible.

The maximal velocity $\left(V_{\max }\right)$ is defined as the maximum rate of reaction when the enzyme active sites are saturated with substrate and the $\mathrm{k}_{\mathrm{cat}}$ is calculated by dividing the $\mathrm{V}_{\max }$ to the ROL concentration in the reaction mixture. As shown in table $2, \mathrm{~V}_{\max }$ and $\mathrm{k}_{\text {cat }}$ decreased after $\mathrm{ROL}$ immobilization on the supports due to the substrate diffusion limit. This behavior has been observed for enzymes which immobilized on different carriers ${ }^{50-52}$. However, because of the larger surface area of MGO, the mass transfer limit is reduced when MGO is used as support and $\mathrm{V}_{\max }$ and $\mathrm{k}_{\text {cat }}$ are increased compared with MNP. According to the $k_{\text {cat }}$ to $K_{m}$ ratio which is an estimation of catalytic efficiency, a significant increase was observed in ROL immobilized on functionalized MGO supports indicating higher catalytic efficiency. The $\mathrm{k}_{\text {cat }} / \mathrm{K}_{\mathrm{m}}$ value for ROL/MGO-AP-GA was 25.83 which was about 4 -fold more than ROL/MGO. It indicates that covalent bonding between the ROL and MGO-AP-GA can be considered as an efficient method for lipase immobilization.

\section{Thermal stability}

The time-course thermal stabilities of all nano-biocatalysts were studied by incubating them at $60^{\circ} \mathrm{C}$ in different time durations (10 to $60 \mathrm{~min}$ ) and evaluation of their residual activities (Figure 11). The residual activity was measured at the optimum conditions after cooling in ice for $30 \mathrm{~min}$ and mentioned as 
thermal stability. Nano-biocatalysts residual activity which incubated at $60^{\circ} \mathrm{C}$ for 0 min considered as control (with $100 \%$ activity). As shown in figure 10, the residual activity of free ROL was decreased by increasing the incubation time. According to the figure, the thermal stability of ROL/MGO is more than ROL/MNP which is due to the more functional groups on MGO compare with MNP. After the functionalization of MGO with AP, electrostatic attractions between ROL and support increased and led to a noticeable improvement in the thermal stability of nano-bio catalyst. The residual activities of ROL/MNP, ROL/MGO, ROL/MGO-AP, and ROL/ MGO-AP-GA after 60 min incubation and at $60{ }^{\circ} \mathrm{C}$ were $13.09 \%, 27.20 \%, 30.59 \%$, and $33.44 \%$ respectively. The ROL/MGO-AP-GA has the highest thermal stability and it demonstrated that enzyme more attraction with support causes more thermal stability. It can be related to the lower flexibility of the enzyme structure when it has more attractions with the support. The lower flexibility makes the enzyme more resistant to the deformation if the temperature keeps on increasing ${ }^{53}$.

\section{Storage stability}

To evaluate the immobilization efficiency, the storage stability of the immobilized enzyme should be considered as an important requirement. The storage stabilities of the free and immobilized ROL were evaluated at two different incubation temperatures $\left(4^{\circ} \mathrm{C}\right.$ and $\left.25^{\circ} \mathrm{C}\right)$. The results are presented in figure 12. As shown, for the free $\mathrm{ROL}$ at $4{ }^{\circ} \mathrm{C}$, almost $39.13 \%$ of initial activity remained after 30 days, while the activities reached about $51.63 \%, 64.27 \%, 70.72 \%$ and $74.49 \%$ of initial activity for ROL/MNP, ROL/MGO, ROL/MGO-AP, and ROL/MGO-AP-GA, respectively. Maximum storage stability was related to ROL/MGOAP-GA which can be attributed to ROL covalent bonding to support. This covalent bonding prevents the conformational change of enzyme and consequently helps to preserve its catalytic activity ${ }^{54}$. Figure 12 also shows the storage stability of nano-biocatalysts at room temperature. The behavior was similar to the examination at $4^{\circ} \mathrm{C}$. However, a total decreasing of storage stability occurred at $25^{\circ} \mathrm{C}$ compare with $4^{\circ} \mathrm{C}$.

\section{Biodiesel production}

GC-MS technique was used for products to analyze. Four FAMEs (Methyl palmitate, Methyl stearate, Methyl (7E,10E)-7,10-hexadecadienoate and Methyl (9Z,12Z,15Z)-9,12,15-octadecatrienoate) as biodiesel were detected in the product mixture via GC-MS. The results of Chlorella vulgaris oil conversion to biodiesel in the presence of immobilized ROL represents in figure 13. The reaction in the presence of ROL/MNP and ROL/MGO showed the lowest biodiesel conversion of $54.14 \%$ and $57.05 \%$, respectively. Since ROL is attached to MNP and MGO via comparatively weak physical adsorption, it is prone to enzyme leaching. Hence it can result in low FAMEs production in comparison with two other nanobiocatalysts. However, a slightgeneral increase of ROL/MGO biodiesel conversion was occurred in order to higher catalytic efficiency of ROL/MGO compared with ROL/MNP.

Biodiesel conversion increased in the presence of ROL/MGO-AP. Amine groups of AP improve the electrostatic interactions due to the negative charge decreasing of the MGO surface as well as decreases 
the steric hindrance of the enzyme. Therefore, enzyme leaching is less likely to occur and subsequently higher productivity. The highest FAMEs conversion was attributed to ROL/MGO-AP-GA. The more stable and resistant biocatalyst in the harsh reaction conditions was prepared by the functionalization of MGO by $A P$ and $G A$. The aldehyde groups in GA react with amine groups of $R O L$ to create covalent double bond $\mathrm{C}=\mathrm{N}$. The bonds prevent changing ROL conformation during reaction time. In addition, the introducing of AP and GA to the supports facilitates the formation of an active complex between enzyme active sites and substrate via creating a larger polar area around the the support surface.

\section{Nano-bio catalysts reusability}

The reusability of nano-biocatalysts was evaluated and results were represented in figure 14 . The best reusing performance was obtained for ROL/MGO-AP-GA among other nano-biocatalysts. The $58.77 \%$ of FAMEs conversion was maintained after five cycles of reactions in the presence of ROL/MGO-AP-GA. The results have proved that covalent bonding between the ROL and support helps the physical strength of nano-bio catalyst to be better. So, the nano-bio catalyst stability was increased and consequently higher biodiesel conversion was obtained over multi-cycle reuse.

\section{Conclusions}

Superparamagnetic nano-biocatalysts composed of immobilized Rhizopus oryzae lipase on graphene oxide supports were used for producing FAMEs as a type of biodiesel from Chlorella vulgaris microalgae oil. This microalga was cultivated in the modified BG-11 medium to increase total biomass lipid (35 wt. $\%)$. ROL immobilization on MGO was performed via covalent and non-covalent linkages. Electrostatic attractions and covalent bonds of ROL to MGO were created via AP and AP-GA as coupling agents. Kinetics parameter, loading capacity, thermal and storage stability of MGO-based nano-biocatalysts were evaluated and compared with free ROL and ROL/MNP. Hybrids of GO and magnetite nanoparticles which used as lipase immobilization supports could increase the catalytic performance of enzyme compare with the bare magnetite nanoparticles. The modification of MGO with AP and AP-GA could enhance the enzyme loading and catalytic efficiency. It can be related to creating an appropriate distance between the support and enzyme. The wider space can reduce steric hindrance as well as fully prevent enzyme intermolecular crosslinking. The catalytic efficiency of ROL/MGO-AP-GA was 4 times higher than the free ROL. The covalent bonding between ROL and the support in ROL/MGO-AP-GA caused the biocatalyst more stable and resistant in the microalgae oil transesterification reaction medium. Therefore, the highest biodiesel conversion and the best reusability performance among other immobilized biocatalysts were presented by ROL/MGO-AP-GA.

\section{Methods}

\section{Materials}


For the preparation of graphene oxide (GO) according to the modified Hummer's method, the chemicals including, sulfuric acid (>98\%), ortho- Phosphoric acid (85\%), potassium permanganate (KMnO4), hydrogen peroxide (30\%), and hydrochloric acid (37\%), were purchased from Merck. Pristine graphite powder was supplied from Fluka Company. The precursors for the synthesis of the functionalized MGO were iron (II) sulfate tetrahydrate $\left(\mathrm{FeSO}_{4} \cdot 4 \mathrm{H}_{2} \mathrm{O}, 99.7 \%\right)$, iron (III) chloride hexahydrate $\left(\mathrm{FeCl}_{3} \cdot 6 \mathrm{H}_{2} \mathrm{O}, 99.0 \%\right)$, ammonia ( $\mathrm{NH}_{4} \mathrm{OH}, 25 \mathrm{wt}$. \%), absolute ethanol, 3-aminopropyl triethoxysilane (AP), and glutaraldehyde (GA) and were purchased from Merck. Rhizopus oryzae lipase (light brown powder, $\geq 30,000 \mathrm{U} / \mathrm{g}$ ) was purchased from Sigma-Aldrich. Reagents for the nano-biocatalysts assay, $p$-nitrophenyl palmitate $(p$ NPP), isopropyl alcohol (99.7\%), bovine serum albumin (BSA), Coomassie Brilliant Blue G-250, Triton X100, and Arabic gum were purchased from Merck. BG-11 medium (Blue-Green medium) components, for the cultivation and maintenance of the microalgae Chlorella vulgaris CCAP were obtained from either Merck. All organic solvents and other chemicals purchased from Merck and were of analytical grade.

\section{Magnetic nanoparticles preparation}

MNPs were synthesized using co-precipitation of $\mathrm{FeCl}_{3} \cdot 6 \mathrm{H}_{2} \mathrm{O}$ and $\mathrm{FeSO}_{4} \cdot 4 \mathrm{H}_{2} \mathrm{O}$ with a 2:1 molar ratio in 90 $\mathrm{cm}^{3}$ deionized water. The aqueous solution was stirred continuously under a nitrogen atmosphere at 85 ${ }^{\circ} \mathrm{C}$. To achieve a solution with $\mathrm{pH}=9$, a certain amount of $25 \%$ ammonia solution was added to it dropwise. After $1 \mathrm{~h}$, the obtained black sediment (MNP) was collected using an external magnetic field and washed several times with deionized water.

\section{Graphene oxide and magnetic graphene oxide preparation}

Graphene oxide (GO) was synthesized using graphite flakes through the modified Hummers' method. One gram of graphite flakes was dispersed in a 9:1 mixture of $\mathrm{H}_{2} \mathrm{SO}_{4} / \mathrm{H}_{3} \mathrm{PO}_{4}$ and stirred for $30 \mathrm{~min}$. The reaction medium was heated up to $50^{\circ} \mathrm{C}$. Then $6 \mathrm{~g}$ of $\mathrm{KMnO}_{4}$ was added slowly to this mixture and stirred $24 \mathrm{~h}$ at $50^{\circ} \mathrm{C}$. The mixture was cooled and maintained below $20^{\circ} \mathrm{C}$, afterward. Subsequently, 200 $\mathrm{mL}$ of frozen deionized water was added gradually to it. The suspension was further treated with hydrogen peroxide $30 \%(5 \mathrm{~mL})$. The solution color turned into yellow and it determined that the reaction was completed. The suspension was washed with $\mathrm{HCl}(1 \mathrm{M})$ to remove any residual ions and acids from the reaction medium. The obtained GO was washed using a 5:1 V/V water: ethanol several times by applying centrifugal force.

Magnetic GO (MGO) was prepared via an in-situ deposition of $\mathrm{Fe}_{3} \mathrm{O}_{4}$ nanoparticles on the surface of $\mathrm{GO}$ with a 1:1 initial mass ratio of $\mathrm{GO}$ and $\mathrm{Fe}_{3} \mathrm{O}_{4}$. In a three-necked flask with a flow of $\mathrm{N}_{2}, 0.05 \mathrm{~g}$ of $\mathrm{FeCl}_{3} \cdot 6 \mathrm{H}_{2} \mathrm{O}$ and $0.1 \mathrm{~g}$ of $\mathrm{FeSO}_{4} \cdot 4 \mathrm{H}_{2} \mathrm{O}$ were dissolved in $50 \mathrm{~mL}$ deionized water. The reaction was followed by the addition of $10 \mathrm{~mL} \mathrm{GO}\left(1 \mathrm{mg} \cdot \mathrm{mL}^{-1}\right)$ to the solution and heated to $80^{\circ} \mathrm{C}$. After $15 \mathrm{~min}, 10 \mathrm{~mL}$ of $25 \%$ ammonia solution was added to the solution until the $\mathrm{pH}$ reached around 9. The reaction was carried out at $85^{\circ} \mathrm{C}$ for $1 \mathrm{~h}$. The black sediment was collected using an external magnetic field and then washed with deionized water three times until the $\mathrm{pH}$ was neutralized. 


\section{Functional magnetic graphene oxide preparation}

For functionalization of MGO with 3-aminopropyl triethoxysilane (AP), $0.05 \mathrm{~g} \mathrm{MGO}$ was dispersed in 4.6 $\mathrm{mL}$ of ethanol and sonicated under $70 \mathrm{kHz}$ frequency. The $0.1 \mathrm{~mL}$ of acetic acid and $0.1 \mathrm{~mL}$ of AP were added to this mixture. After $5 \mathrm{~h}$ shaking at room temperature, MGO-AP was prepared. The product was separated using an external magnetic field and washed with deionized water. To functionalize MGO with both AP and GA (MGO-AP-GA), $0.04 \mathrm{~mL}$ of GA solution was added to the synthesized MGO-AP and shaken for $2 \mathrm{~h}$ at room temperature.

\section{Enzyme immobilization}

In a typical enzyme immobilization experiment, $5 \mathrm{mg}$ of each supports (MNP, MGO, MGO-AP, MGO-AP-GA) were suspended to $1 \mathrm{~mL}$ phosphate buffer $(100 \mathrm{mM})$ at $\mathrm{pH}=7.5$ and then added to ROL solution with different concentrations. The samples were shaken at $4{ }^{\circ} \mathrm{C}$ for $17 \mathrm{~h}$ in a shaking incubator at a stirring speed of $120 \mathrm{rpm}$. The solids were isolated from the suspension under a magnetic field and then washed five times with the buffer solution. A schematic view of support preparation and enzyme immobilization was presented in figure 1. The loaded protein content was measured with Bradford's method using BSA as a standard. The immobilization efficiency was defined as equation 1.

Eq 1: Immobilization efficiency $=\frac{\text { Initial } \text { ROL weight }(\mathrm{mg})-\text { not bounded } R O L(\mathrm{mg})}{\text { Weight of support }} \times 100$

\section{Lipolytic activity and kinetic parameters}

The spectrophotometric enzyme assay was applied to evaluate the lipolytic activity and kinetic parameters of free and immobilized ROL. For this purpose, the enzymatic hydrolysis of $p$-NPP as the model substrate was utilized. Substrate solution was prepared by mixing 1 volume of $p$-NPP solution (16.5 mM $p$-NPP solution in isopropanol) and 9 volume of buffer solution containing $0.04 \mathrm{~mL}$ Triton X100 and $0.01 \mathrm{~g}$ Arabic gum in $10 \mathrm{~mL}$ PBS; $100 \mathrm{mM}$. Then, $8.6 \mathrm{mg}$ of ROL was added to a certain amount of substrate solution to start the reaction and kept it $5 \mathrm{~min}$. The release of $p$-nitrophenol was measured using UV-visible spectrophotometry (Varian Cary 100 Spectrophotometer) at $410 \mathrm{~nm}$. One unit of the enzyme $(1 \mathrm{U})$ was defined as the amount of biocatalyst that released $1 \mu \mathrm{mol}$ of $p$-nitrophenol per minute under the assay condition. The kinetic parameters $\left(\mathrm{V}_{\max }\right.$ and $\left.\mathrm{K}_{\mathrm{m}}\right)$ of all the nano-biocatalysts for $p$-NPP hydrolysis were obtained from Michaelis-Menten equation and Lineweaver-Burk plots ${ }^{55}$. Lineweaver-Burk plots were created by measuring initial velocity $\left(V_{0}\right)$ at different concentrations from 0.1 to $2 \mathrm{mM}$ of the substrate $(S)$ in the assay mixtures under the experimental conditions. The turnover number $\left(k_{\text {cat }}\right)$ and the specificity constant $\left(\mathrm{k}_{\mathrm{cat}} / \mathrm{K}_{\mathrm{m}}\right)$ for all nano-biocatalysts were also determined and compared. The determination of lipolytic activity and kinetic parameters were carried out in triplicate. Statistical analysis 
was performed to evaluate the differences between the study groups. Analysis of variance (ANOVA) and the least significant difference (LSD) posthoc tests was used for statistical analysis. P-values less than 0.05 were considered significant.

\section{Time-course thermostability and storage stability}

For evaluation of free and immobilized ROL thermostability, all samples were incubated at $60{ }^{\circ} \mathrm{C}$ over different periods of time $(0,10,20,30,40,50$ and $60 \mathrm{~min})$. The nano-biocatalysts residual activity was measured after cooling in the ice bath for $30 \mathrm{~min}$. The storage stability of free and immobilized ROL was assayed at $4^{\circ} \mathrm{C}$ and $25^{\circ} \mathrm{C}$ and residual activity was measured at the gap of six days for 30 days period. All nano-biocatalysts residual activities were investigated based on p-NPP hydrolysis in optimum conditions.

\section{Biomass cultivation, lipid extraction, and biodiesel production}

Chlorella vulgaris CCAP (211/19) was cultivated in a nitrogen-starvation modified BG11. Briefly, a modified BG11 culture was achieved in several $4 \mathrm{~L}$ glassy tubular photo-bioreactor under continuous 4 Klux cool-white LED with an air pump for 12 days. Microalgae were grown in a modified BG11 medium during the first 6 days. For the second 6 days, cultivation was continued under nitrate-starvation conditions with the aim of increasing biomass lipid content. Afterward, the microalgae were harvested using centrifugation (40 min, $4000 \mathrm{rpm}$ ) and washed twice with deionized water. The total lipid content per algal biomass ( $>35 \%$ dry weight) was determined via the sulpho-phospho-vanillin (SPV) method ${ }^{56}$. The lipid extraction was performed using liquid-liquid extraction.

Transesterification reaction was carried out to convert the extracted microalgae lipid to fatty acid methyl esters (FAMEs) in the presence of immobilized ROL at $45^{\circ} \mathrm{C}$ for $24 \mathrm{~h}$. In a typical reaction, $8.6 \mathrm{mg}$ of nano-bio catalyst was added to $0.5 \mathrm{~mL}$ of extracted lipid dissolved in n-Hexane $\left(5 \mathrm{mg} . \mathrm{cm}^{-3}\right)$ and $0.15 \mathrm{~mL}$ of methanol was added in three reaction time steps of 0,8 , and $12 \mathrm{~h}$ to avoid ROL deactivation. At the end of the reaction, two-phase media appeared. The nano-bio catalyst was collected using an external magnetic field from the lower phase (aqueous phase) which consisted of glycerol and other water-soluble components. Subsequently, the upper phase contained FAMEs diluted in hexane was subjected to GC-MS analysis. Biocatalysts were reused in the reactions with the mentioned condition. For reusing experiments, each nano-bio catalyst was washed with hexane for removing the adhered algae oil before using it in the next step. Reaction conversion was defined as the weight ratio of the produced FAMEs to the initial algae oil.

\section{Nano-biocatalyst characterization and product analysis}

The interactions and the chemical bonding of nanoparticles and enzymes were inspected by Fouriertransform infrared spectroscopy (FTIR) analysis via Bruker Tensor 27 Fourier-transform infrared. The spectra recorded in the range of $4000 \mathrm{~cm}^{-1}$ to $400 \mathrm{~cm}^{-1}$ using the $\mathrm{KBr}$ matrix. The X-ray field emission scanning electron microscopy (TESCAN MIRA3 XMU FESEM) was applied for MNP, MGO, and ROL/MGO- 
AP-GA surface morphology. Element distribution was also evaluated from the energy dispersive spectrometer analysis (EDS-Element mapping). The identification of crystalline phases in all catalysts was performed by powder X-ray diffraction using a Philips Analytical X-ray diffractometer (XPert MPD) with monochromatized $\mathrm{Cu} / \mathrm{KÂ}$ radiation. Vibrating sample magnetometer (VSM, Meghnatis Daghigh Kavir Co., Iran) was applied to measuring the magnetization of support. The chemical compositions of product mixtures were analyzed using a GC-MS system of HP Agilent Technology 6890 Network Gas Chromatogram System with column HP-5MS (Length: $30 \mathrm{~m}$, internal diameter: $0.25 \mathrm{~mm}$, Film thickness: $0.25 \mu \mathrm{m}$ and Material: Fused silica) and Mass Spectrometer (5973 Network Mass Selective Detector). The carrier gas was He with $99.999 \%$ purity and the temperature of the injector was set at $250^{\circ} \mathrm{C}$. A temperature program was used for the column (Initial temperature: $60^{\circ} \mathrm{C}$, Initial time: 2 min, Temperature rising rate: $10^{\circ} \mathrm{C} \cdot \mathrm{min}^{-1}$ up to $200^{\circ} \mathrm{C}$ and $5 \mathrm{oC}^{\circ} \mathrm{min}^{-1}$ to $240^{\circ} \mathrm{C}$, and Final temperature: $240{ }^{\circ} \mathrm{C}$ for $7 \mathrm{~min}$ ). The temperature of the ion source of the mass spectrometer was set at $250^{\circ} \mathrm{C}$, and the ionization mode was electron impact with an electron energy of $70 \mathrm{eV}$. The internal standard method was used for the determination of FAMEs and Heptadecanoic acid methyl ester (C18:0) was selected as standard material.

\section{Abbreviations}

FAME: Fatty acid methyl esters,ROL: Rhizopus oryzae lipase, GO: Graphene oxide, MNP: Magnetic nanoparticles $\left(\mathrm{Fe}_{3} \mathrm{O}_{4}\right)$, AP: 3-aminopropyl triethoxysilane, GA: Glutaraldehyde, MGO: Magnetic graphene oxide, ROL/MNP: ROL immobilized on MNP, ROL/MGO: ROL immobilized on MGO, ROL/MGO-AP: ROL immobilized on MGO-AP, ROL/MGO-AP-GA: ROL immobilized on MGO-AP-GA, $p$-NPP: $p$-nitrophenyl palmitate, BG-11: Blue-Green 11, FESEM: Field emission scanning electron microscopy, EDS: Energy dispersive spectrometer analysis, VSM: Vibrating sample magnetometer, FTIR: Fourier-transform infrared spectroscopy, XRD: X-ray diffraction, AFM: Atomic force microscopy, GC-MS: Gas Chromatography-Mass Spectroscopy, ANOVA: Analysis of variance, LSD: The least significant difference

\section{Declarations}

\section{Acknowledgments}

The authors would like to gratefully thank from Iranian National Science Foundation (INSF) for the financial support of this project.

\section{Authors' contributions}

Nematian T. wrote the main manuscript text and was involved in all tests directly. Shakeri A. was a chemistry supervisor of the research. He also edited the manuscript. Salehi Z. as the corresponding author sponsored the study and made all the arrangements. She also edited the manuscript. She was a chemical engineering supervisor of the research. Saboury A. as the co-corresponding author consulted 
frequently over the course of the research and provided some analysis in IBB center. He also edited the manuscript.

\section{Funding}

It was not a funded project

\section{Availability of data and materials}

All data generated or analyzed during this study are included in the manuscript.

\section{Ethics approval and consent to participate}

Not applicable

\section{Consent for publication}

All authors agree with submission to Biotechnology for Biofuel.

\section{Competing interests}

There are no competing interests associated with this manuscript.

\section{References}

1. Kotcher J, Maibach E, Choi W-T, Fossil fuels are harming our brains: identifying key messages about the health effects of air pollution from fossil fuels. BMC public health 2019;19(1):1-12.

2. Xu J, Modeling of Correlation between Fossil Fuel Combustion Products and Atmospheric Environmental Pollution. Ekoloji Dergisi 2019(107).

3. Barati M, Kahid Baseri G, Hydrogen, alcohols, and ethers production from biomass in supercritical methanol-subcritical water medium with $\mathrm{Cu}-\mathrm{K}$ nanocatalysts. Environmental Progress \& Sustainable Energy 2018;37(2):861-9.

4. Pollitt KJG, Chhan D, Rais K, Pan K, Wallace JS, Biodiesel fuels: A greener diesel? A review from a health perspective. Science of the total environment 2019.

5. Dutta A, Impact of carbon emission trading on the European Union biodiesel feedstock market. Biomass and Bioenergy 2019;128:105328.

6. Kolli VK, Gadepalli S, Barma JD, Maddali MK, Barathula S, reddy Siddavatam NK, Establishment of lower exhaust emissions by using EGR coupled low heat loss diesel engine with fuel blends of 
microalgae biodiesel-oxygenated additive DEE-antioxidant DPPD. Thermal Science and Engineering Progress 2019;13:100401.

7. Giakoumis EG, Sarakatsanis CK, Estimation of biodiesel cetane number, density, kinematic viscosity and heating values from its fatty acid weight composition. Fuel 2018;222:574-85.

8. Rashid N, Ryu AJ, Jeong KJ, Lee B, Chang Y-K, Co-cultivation of two freshwater microalgae species to improve biomass productivity and biodiesel production. Energy Conversion and Management 2019;196:640-8.

9. Rathnam VM, Madras G, Conversion of Shizochitrium limacinum microalgae to biodiesel by noncatalytic transesterification using various supercritical fluids. Bioresource technology 2019;288:121538.

10. Singh R, Kumar A, Sharma YC, Biodiesel synthesis from microalgae (Anabaena PCC 7120) by using barium titanium oxide (Ba2TiO4) solid base catalyst. Bioresource technology 2019;287:121357.

11. Nematian T, Salehi Z, Shakeri A, Conversion of bio-oil extracted from Chlorella vulgaris micro algae to biodiesel via modified superparamagnetic nano-biocatalyst. Renewable Energy 2020;146:1796-804.

12. Aghilinategh $M$, Barati $M$, Hamadanian $M$, Supercritical methanol for one put biodiesel production from chlorella vulgaris microalgae in the presence of $\mathrm{CaO} / \mathrm{TiO} 2$ nano-photocatalyst and subcritical water. Biomass and Bioenergy 2019;123:34-40.

13. Sakarika M, Kornaros M, Chlorella vulgaris as a green biofuel factory: Comparison between biodiesel, biogas and combustible biomass production. Bioresource technology 2019;273:237-43.

14. Basumatary S, Transesterification with heterogeneous catalyst in production of biodiesel: A Review. Journal of Chemical and Pharmaceutical Research 2013;5(1):1-7.

15. Jothiramalingam R, Wang MK, Review of recent developments in solid acid, base, and enzyme catalysts (heterogeneous) for biodiesel production via transesterification. Industrial \& Engineering Chemistry Research 2009;48(13):6162-72.

16. Dhawane SH, Chowdhury S, Halder G, Lipase immobilised carbonaceous catalyst assisted enzymatic transesterification of Mesua ferrea oil. Energy Conversion and Management 2019;184:671-80.

17. Encinar JM, González JF, Sánchez N, Nogales-Delgado S, Sunflower oil transesterification with methanol using immobilized lipase enzymes. Bioprocess and biosystems engineering 2019;42(1):157-66.

18. e Cunha DB, Bartkevihi L, Robert J, Cipolatti E, Ferreira A, Oliveira D, Gomes-Neto F, Almeida R, Fernandez-Lafuente R, Freire D, Structural differences of commercial and recombinant lipase B from Candida antarctica: An important implication on enzymes thermostability. International journal of biological macromolecules 2019;140:761-70.

19. Zhou X, Li H, Zheng L, Directly covalent immobilization of Candida antarctica lipase B on oxidized aspen powder by introducing poly-lysines: An economical approach to improve enzyme performance. International journal of biological macromolecules 2019;133:226-34.

20. Pinheiro BB, Rios NS, Aguado ER, Fernandez-Lafuente R, Freire TM, Fechine PB, dos Santos JC, Gonçalves LR, Chitosan activated with divinyl sulfone: a new heterofunctional support for enzyme 
immobilization. Application in the immobilization of lipase B from Candida antarctica. International journal of biological macromolecules 2019;130:798-809.

21. Wan D, Tian L, Li X, Li B, Zhang Q, A versatile strategy for enzyme immobilization: Fabricating lipase/inorganic hybrid nanostructures on macroporous resins with enhanced catalytic properties. Biochemical Engineering Journal 2018;139:101-8.

22. Auriemma F, De Rosa C, Malafronte A, Di Girolamo R, Santillo C, Gerelli Y, Fragneto G, Barker R, Pavone V, Maglio O, Nano-in-nano approach for enzyme immobilization based on block copolymers. ACS applied materials \& interfaces 2017;9(34):29318-27.

23. Kumar A, Park GD, Patel SK, Kondaveeti S, Otari S, Anwar MZ, Kalia VC, Singh Y, Kim SC, Cho B-K, $\mathrm{SiO} 2$ microparticles with carbon nanotube-derived mesopores as an efficient support for enzyme immobilization. Chemical Engineering Journal 2019;359:1252-64.

24. Salehi Z, Ghahfarokhi HH, Kodadadi AA, Rahimnia R, Thiol and urea functionalized magnetic nanoparticles with highly enhanced loading capacity and thermal stability for lipase in transesterification. Journal of industrial and engineering chemistry 2016;35:224-30.

25. Suo H, Xu L, Xu C, Chen H, Yu D, Gao Z, Huang H, Hu Y, Enhancement of catalytic performance of porcine pancreatic lipase immobilized on functional ionic liquid modified Fe304-Chitosan nanocomposites. International journal of biological macromolecules 2018;119:624-32.

26. Itoh T, Shibuya Y, Yamaguchi A, Hoshikawa Y, Tanaike O, Tsunoda T, Hanaoka T-a, Hamakawa S, Mizukami F, Hayashi A, High-performance bioelectrocatalysts created by immobilization of an enzyme into carbon-coated composite membranes with nano-tailored structures. Journal of Materials Chemistry A 2017;5(38):20244-51.

27. Babadi AA, Bagheri S, Hamid SBA, Progress on implantable biofuel cell: Nano-carbon functionalization for enzyme immobilization enhancement. Biosensors and Bioelectronics 2016;79:850-60.

28. Romero-Arcos M, Pérez-Robles JF, Garnica-Romo MG, Luna-Martinez MS, Gonzalez-Reyna M, Synthesis and functionalization of carbon nanotubes and nanospheres as a support for the immobilization of an enzyme extract from the mushroom Trametes versicolor. Journal of Materials Science 2019;54(17):11671-81.

29. Adeel M, Bilal M, Rasheed T, Sharma A, Iqbal HM, Graphene and graphene oxide: functionalization and nano-bio-catalytic system for enzyme immobilization and biotechnological perspective. International journal of biological macromolecules 2018;120:1430-40.

30. Asmat S, Husain Q, Exquisite stability and catalytic performance of immobilized lipase on novel fabricated nanocellulose fused polypyrrole/graphene oxide nanocomposite: Characterization and application. International journal of biological macromolecules 2018;117:331-41.

31. Dutta N, Saha MK, Immobilization of a Mesophilic Lipase on Graphene Oxide: Stability, Activity, and Reusability Insights. Methods in enzymology 2018;609:247-72.

32. Patel V, Gajera H, Gupta A, Manocha L, Madamwar D, Synthesis of ethyl caprylate in organic media using Candida rugosa lipase immobilized on exfoliated graphene oxide: Process parameters and 
reusability studies. Biochemical engineering journal 2015;95:62-70.

33. Wang J, Yu S, Feng F, Lu L, Simultaneous purification and immobilization of laccase on magnetic zeolitic imidazolate frameworks: recyclable biocatalysts with enhanced stability for dye decolorization. Biochemical Engineering Journal 2019:107285.

34. He J, Sun S, Zhou Z, Yuan Q, Liu Y, Liang H, Thermostable enzyme-immobilized magnetic responsive Ni-based metal-organic framework nanorods as recyclable biocatalysts for efficient biosynthesis of S-adenosylmethionine. Dalton Transactions 2019;48(6):2077-85.

35. Sherlala A, Raman A, Bello M, Synthesis and characterization of magnetic graphene oxide for arsenic removal from aqueous solution. Environmental technology 2019;40(12):1508-16.

36. Ninwiwek N, Hongsawat $P$, Punyapalakul P, Prarat $P$, Removal of the antibiotic sulfamethoxazole from environmental water by mesoporous silica-magnetic graphene oxide nanocomposite technology: Adsorption characteristics, coadsorption and uptake mechanism. Colloids and Surfaces A: Physicochemical and Engineering Aspects 2019;580:123716.

37. Zubir NA, Yacou C, Motuzas J, Zhang X, Zhao XS, da Costa JCD, The sacrificial role of graphene oxide in stabilising a Fenton-like catalyst GO-Fe 304 . Chemical Communications 2015;51(45):9291-3.

38. Yang H-W, Hua M-Y, Chen S-L, Tsai R-Y, Reusable sensor based on high magnetization carboxylmodified graphene oxide with intrinsic hydrogen peroxide catalytic activity for hydrogen peroxide and glucose detection. Biosensors and Bioelectronics 2013;41:172-9.

39. Badoei-dalfard A, Karami Z, Malekabadi S, Construction of CLEAs-lipase on magnetic graphene oxide nanocomposite: An efficient nanobiocatalyst for biodiesel production. Bioresource technology 2019;278:473-6.

40. Sharma A, Meena KR, Kanwar SS, Molecular characterization and bioinformatics studies of a lipase from Bacillus thermoamylovorans BHK67. International journal of biological macromolecules 2018;107:2131-40.

41. Sun X, Luo D, Liu J, Evans DG, Monodisperse chemically modified graphene obtained by density gradient ultracentrifugal rate separation. Acs Nano 2010;4(6):3381-9.

42. Marcano DC, Kosynkin DV, Berlin JM, Sinitskii A, Sun Z, Slesarev A, Alemany LB, Lu W, Tour JM, Improved synthesis of graphene oxide. ACS nano 2010;4(8):4806-14.

43. Li W, Xue F, Li Q, Modification of bismaleimide resin by using Y-aminopropyl triethoxysilane functionalised graphene oxide. Plastics, Rubber and Composites 2018;47(5):187-91.

44. Kong J, Yu S, Fourier transform infrared spectroscopic analysis of protein secondary structures. Acta biochimica et biophysica Sinica 2007;39(8):549-59.

45. Asmat S, Husain Q, Azam A, Lipase immobilization on facile synthesized polyaniline-coated silverfunctionalized graphene oxide nanocomposites as novel biocatalysts: stability and activity insights. RSC Advances 2017;7(9):5019-29.

46. Huang J-J, Yuan YJ, A sedimentation study of graphene oxide in aqueous solution using gradient differential centrifugation. Physical Chemistry Chemical Physics 2016;18(17):12312-22. 
47. Bini RA, Marques RFC, Santos FJ, Chaker JA, Jafelicci Jr M, Synthesis and functionalization of magnetite nanoparticles with different amino-functional alkoxysilanes. Journal of magnetism and magnetic materials 2012;324(4):534-9.

48. Feng X, Improved Lipase Immobilization on Woollen Cloth and Its Application in a Novel Spinning Cloth Disc Reactor. ResearchSpace@ Auckland; 2014.

49. Rahimizadeh $P$, Najavand $S$, Pazhang $M, A$ comparative study of activity and stability of the free and the immobilized endoglucanase from Alicyclobacillus acidocaldarius. Biomacromolecular Journal 2015;1(2):167-76.

50. Aghababaie M, Beheshti M, Razmjou A, Bordbar A-K, Covalent immobilization of Candida rugosa lipase on a novel functionalized Fe304@ SiO2 dip-coated nanocomposite membrane. Food and Bioproducts Processing 2016;100:351-60.

51. Karra-Châabouni M, Bouaziz I, Boufı S, do Rego AMB, Gargouri Y, Physical immobilization of Rhizopus oryzae lipase onto cellulose substrate: activity and stability studies. Colloids and Surfaces B: Biointerfaces 2008;66(2):168-77.

52. de Mello MD, Cordeiro D, Costa LT, Follmer C, Catalytic properties of lipases immobilized onto ultrasound-treated chitosan supports. Biotechnology and bioprocess engineering 2013;18(6):1090100.

53. Tan Y, Ma S, Liu C, Yu W, Han F, Enhancing the stability and antibiofilm activity of DspB by immobilization on carboxymethyl chitosan nanoparticles. Microbiological research 2015;178:35-41.

54. Bolibok P, Wiśniewski M, Roszek K, Terzyk AP, Controlling enzymatic activity by immobilization on graphene oxide. The Science of Nature 2017;104(3-4):36.

55. Puskas JE, Kantor J, Shrikhande G, Reaction engineering with enzymes: A relatively uncharted territory. AIChE Journal 2017;63(1):266-72.

56. Park J, Jeong HJ, Yoon EY, Moon SJ, Easy and rapid quantification of lipid contents of marine dinoflagellates using the sulpho-phospho-vanillin method. Algae 2016;31(4):391-401.

\section{Tables}

Table 1: Zeta potential measurement of immobilized ROL

\begin{tabular}{|l|c|}
\hline Samples & Zeta potential $(\mathrm{mV})$ \\
\hline MNP & -25.84 \\
\hline MGO & -33.58 \\
\hline MGO-AP & -17.46 \\
\hline MGO-AP-GA & -20.24 \\
\hline
\end{tabular}

Table 2: The kinetic parameters of free and immobilized ROL. 


\begin{tabular}{|l|c|c|c|c|}
\hline & $\mathrm{K}_{\mathrm{m}}(\mathrm{mM})$ & $\mathrm{V}_{\max }\left(\mu \mathrm{M} \cdot \mathbf{m i n}^{-1}\right)$ & $\mathbf{k}_{\text {cat }}\left(\mathbf{m i n}^{-1}\right)$ & $\mathbf{k}_{\text {cat }} / \mathbf{K}_{\mathrm{m}}\left(\mathbf{m i n}^{-1} \cdot \mathbf{m M}^{-1}\right)$ \\
\hline ROL & $16.45 \pm 0.46$ & $541.52 \pm 26.68$ & $115.22 \pm 7.94$ & 7.01 \\
\hline ROL/MNP & $12.25 \pm 0.54$ & $212.77 \pm 11.11$ & $45.26 \pm 4.26$ & 3.69 \\
\hline ROL/MGO & $12.67 \pm 0.62$ & $336.98 \pm 12.42$ & $71.69 \pm 6.35$ & 5.91 \\
\hline ROL/MGO-AP & $4.01 \pm 0.22$ & $357.23 \pm 8.24$ & $76.55 \pm 5.18$ & 18.95 \\
\hline ROL/MGO-AP-GA & $3.04 \pm 0.18$ & $369.12 \pm 9.83$ & $78.53 \pm 6.76$ & 25.83 \\
\hline
\end{tabular}

Figures 


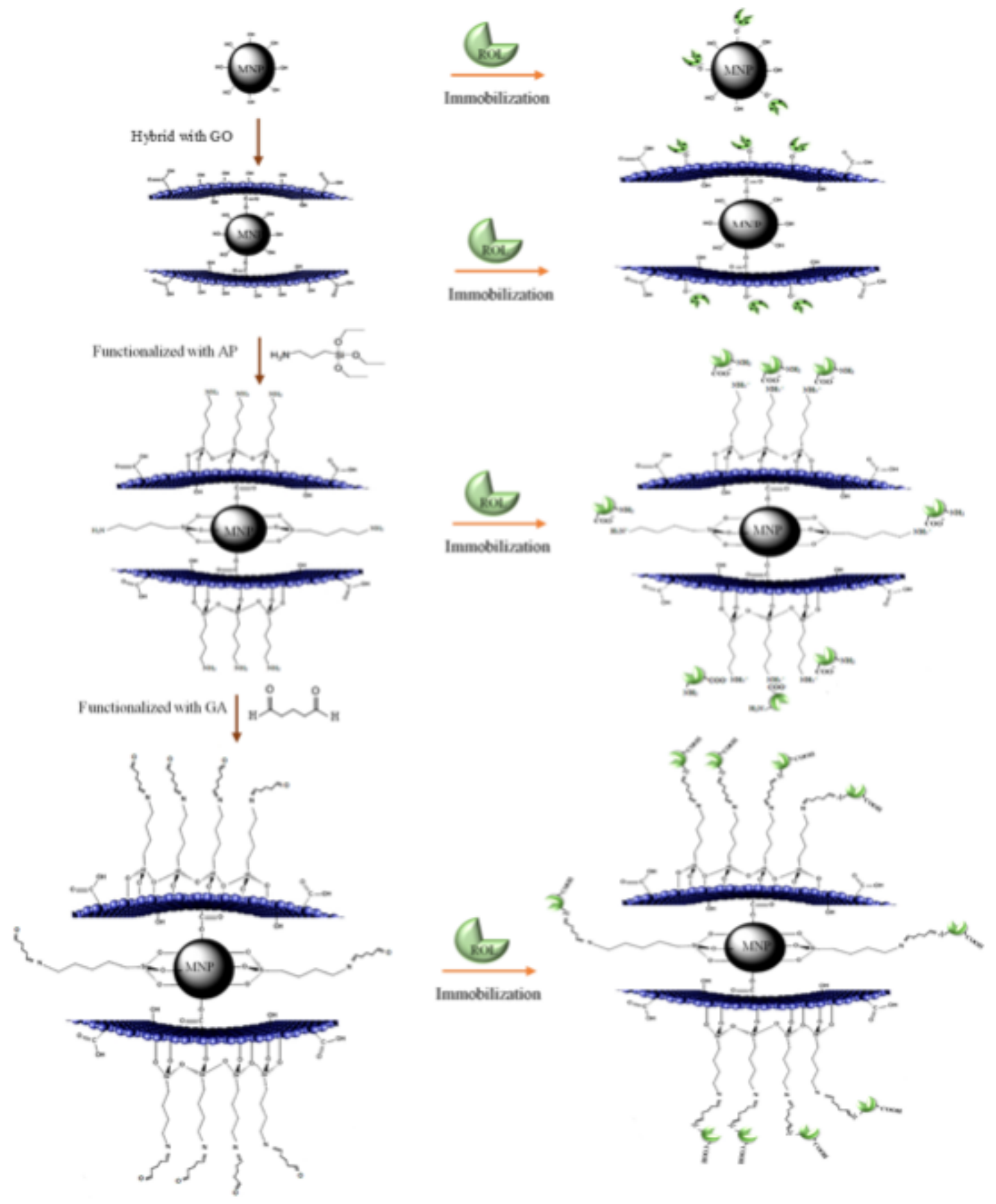

Figure 1

A schematic view of support preparation and enzyme immobilization. 

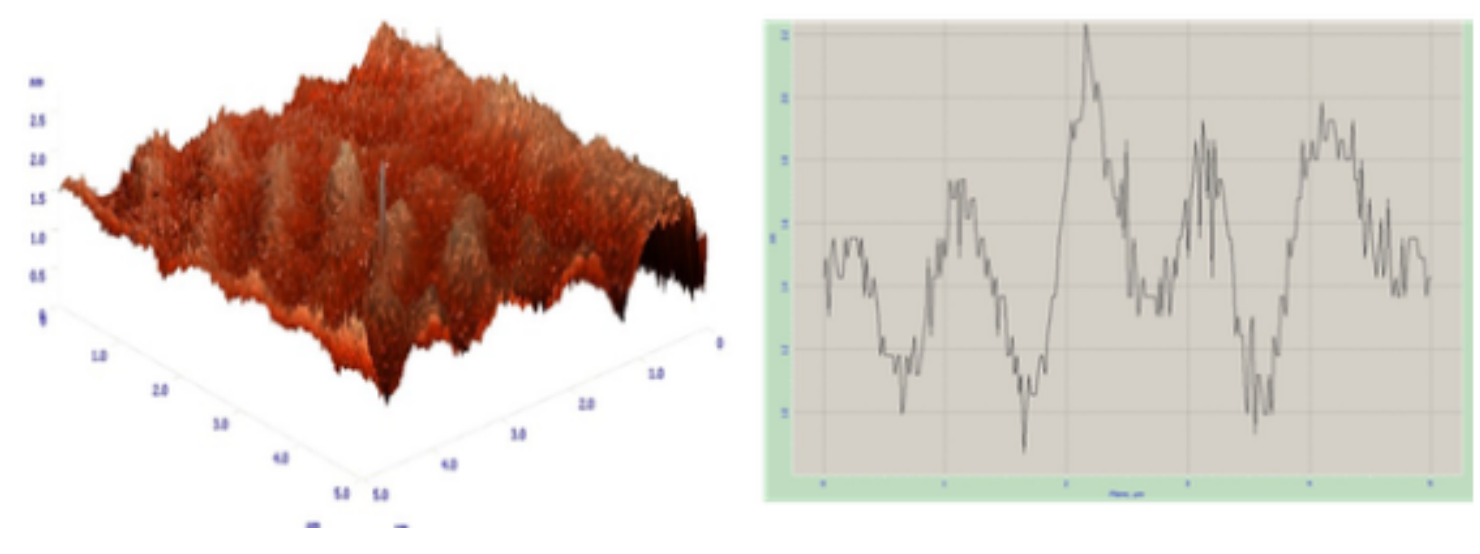

Figure 2

The AFM image of GO sheets and corresponding height profile.

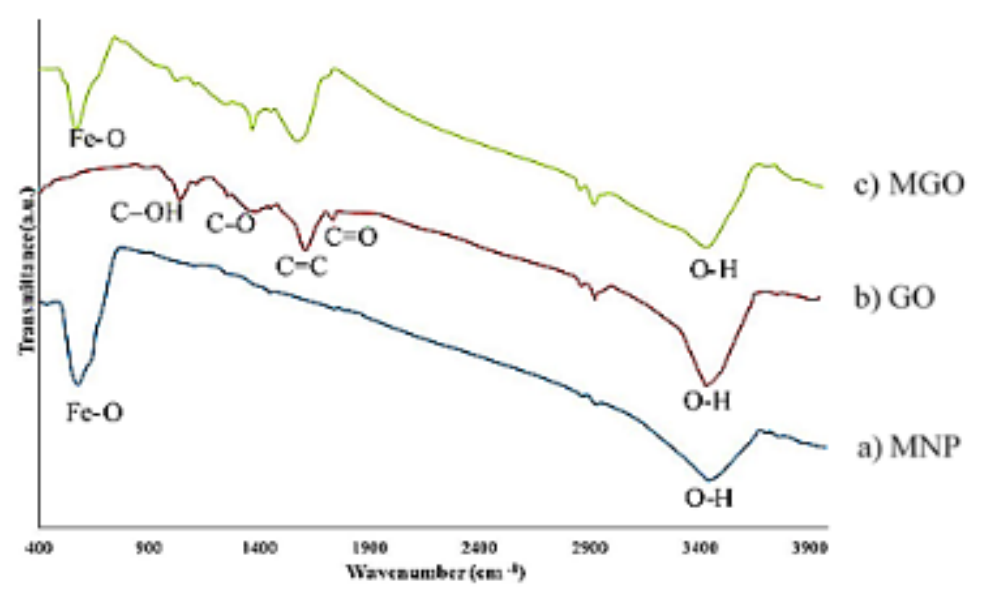

Figure 3

The FTIR spectra of (a) MNP, (b) GO, and (c) MGO.

ed successful immobilization of ROL on MGO-AP-GA 45 .

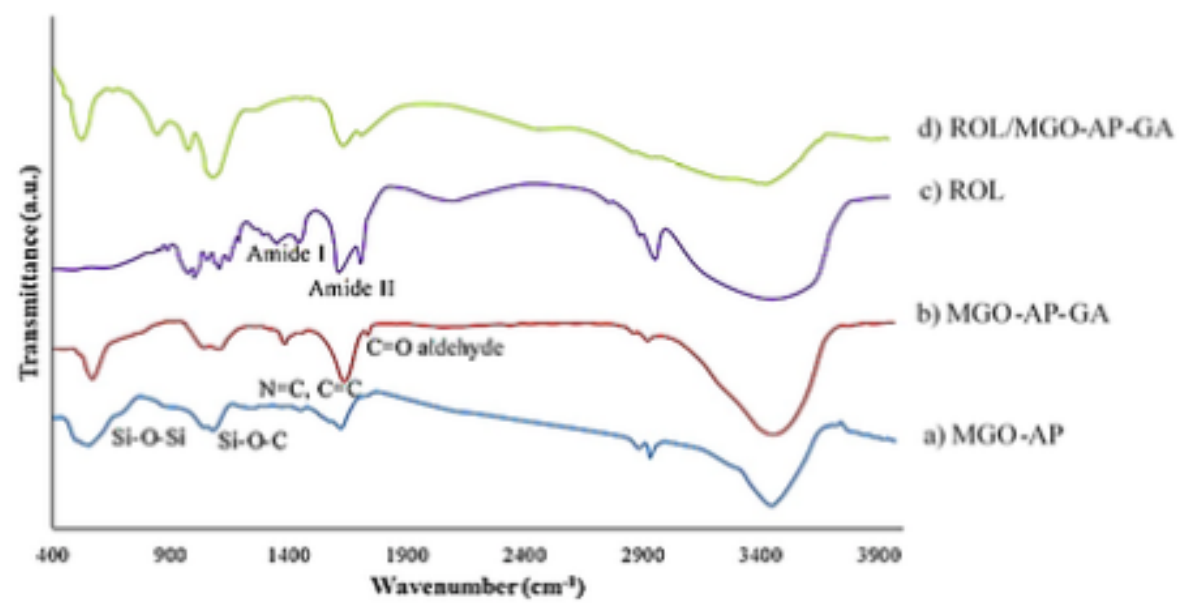

Figure 4

The FTIR spectra (a) MGO-AP, (b) MGO-AP-GA, (c) ROL, and (d) ROL/MGO-AP-GA. 


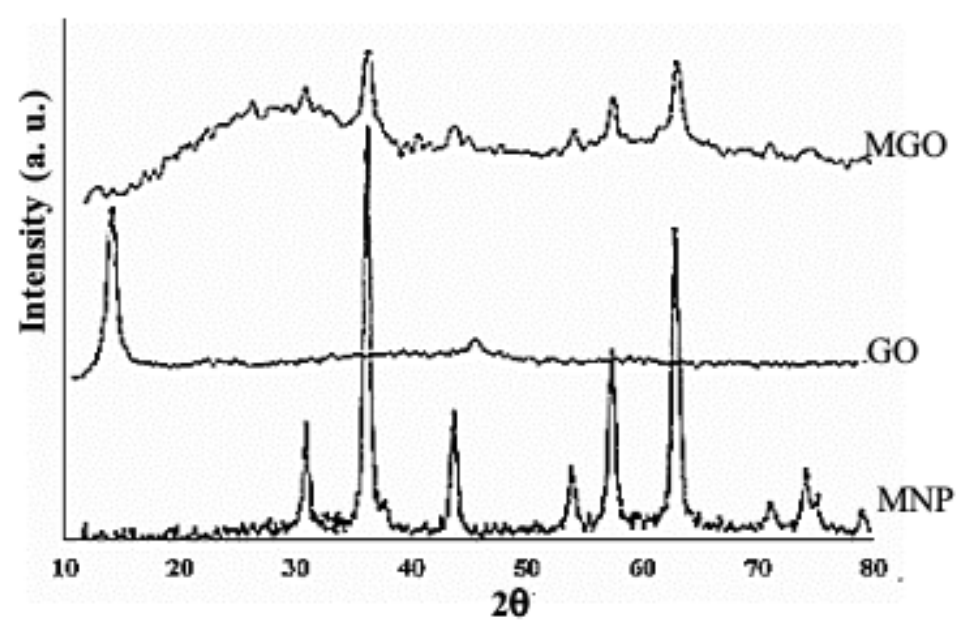

Figure 5

The XRD patterns of a) MNP, b) GO, and c) MGO.

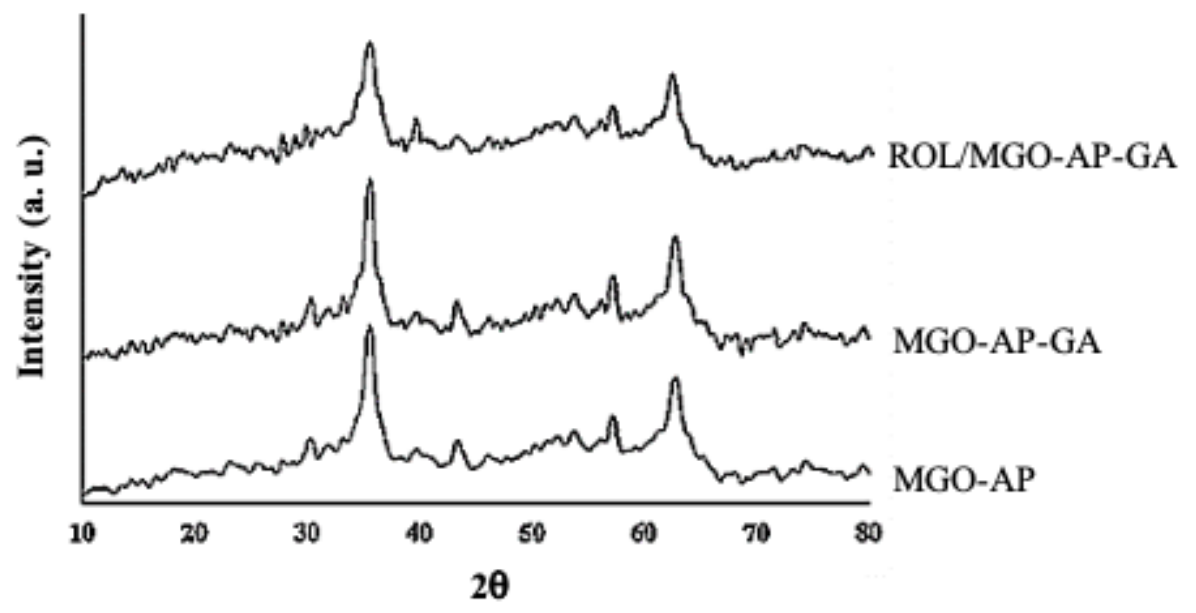

Figure 6

The XRD patterns of a) MGO-AP, b) MGO-AP-GA, and c) ROL/MGO-AP-GA. 


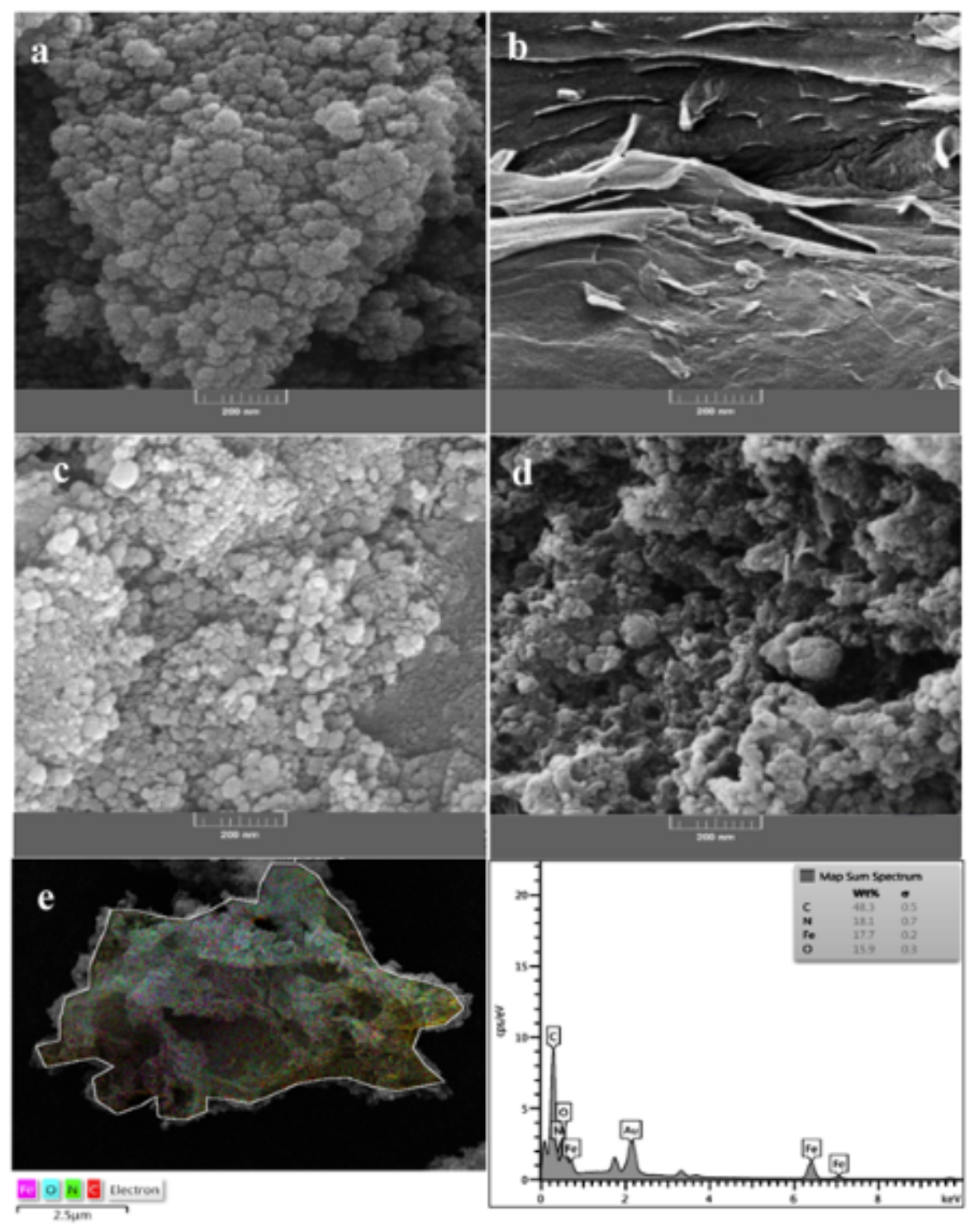

\section{Figure 7}

The FESEM micrographs of a) MNP, b) GO, c) MGO, and d) ROL/MGO-AP-GA as well as the EDS elemental mapping of e) ROL/MGO-AP-GA. 


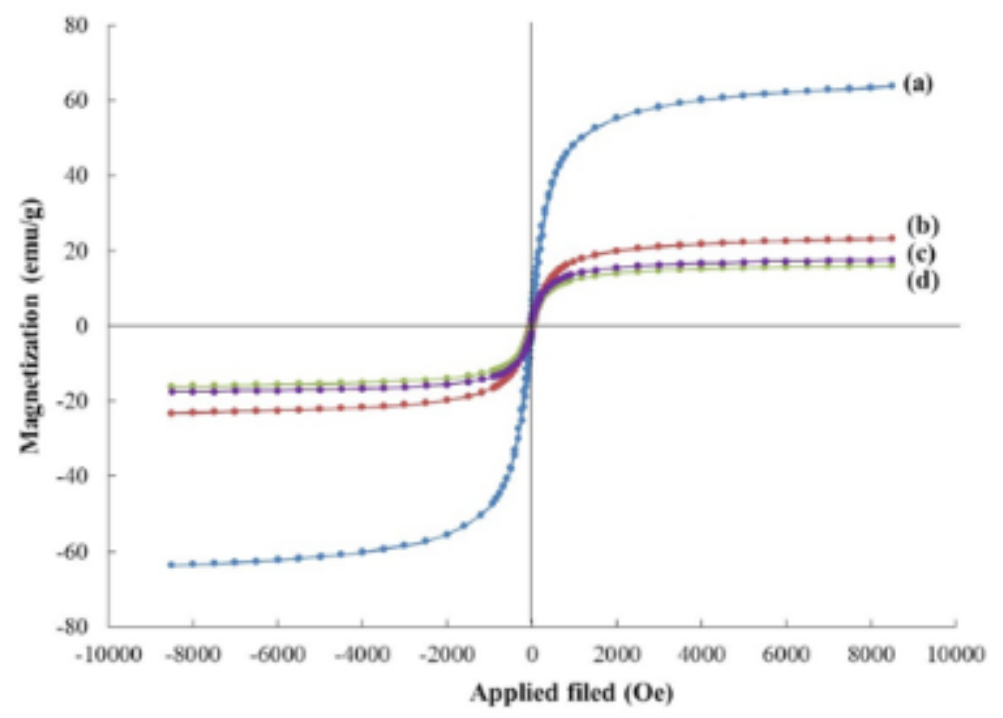

Figure 8

The VSM analysis for a) MNP, b) MGO, c) MGO-AP and d) MGO-AP-GA.
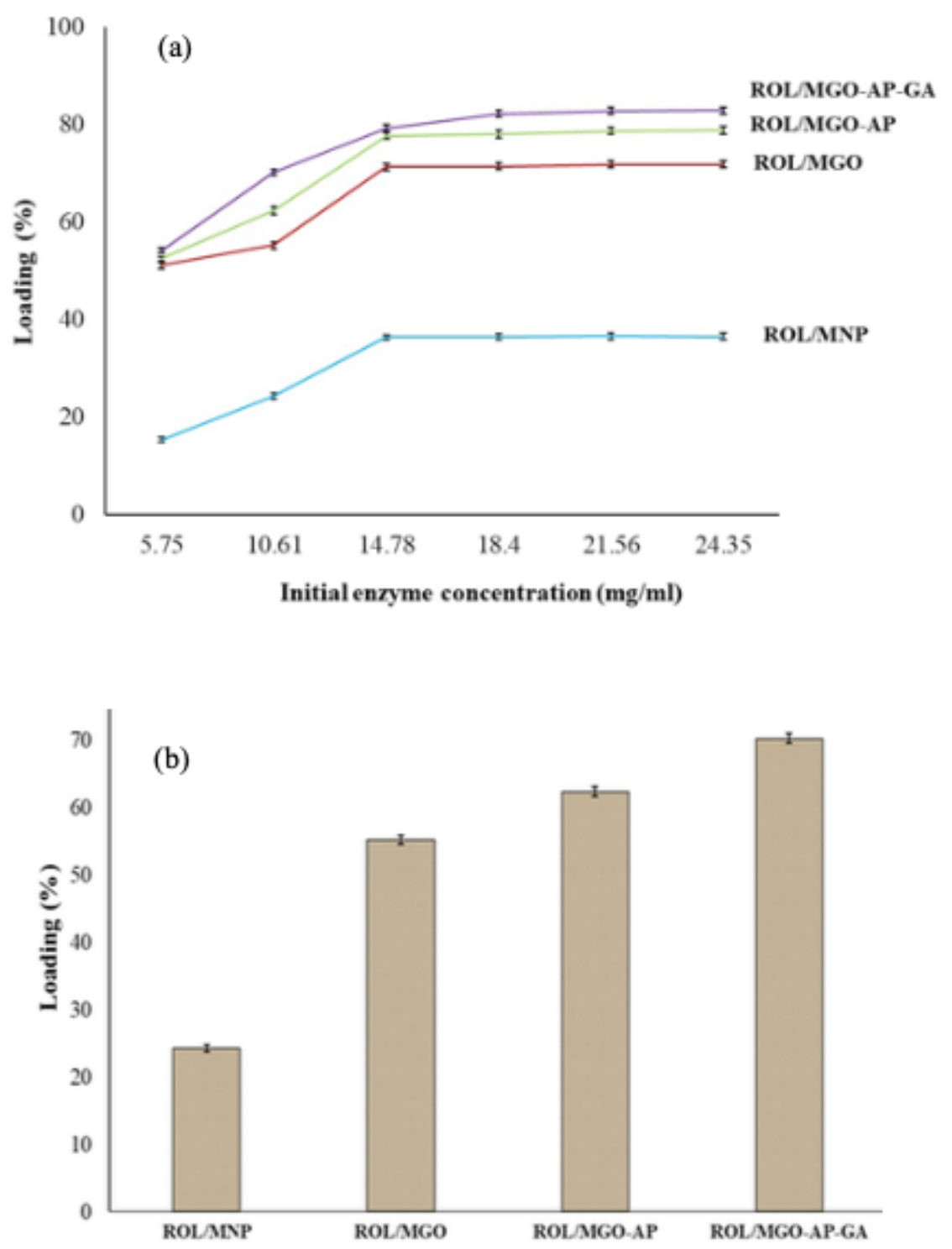

Page $24 / 27$ 
Figure 9

Loading capacity of supports for different ROL initial concentrations (a), and the comparison of supports maximum capacity (b).

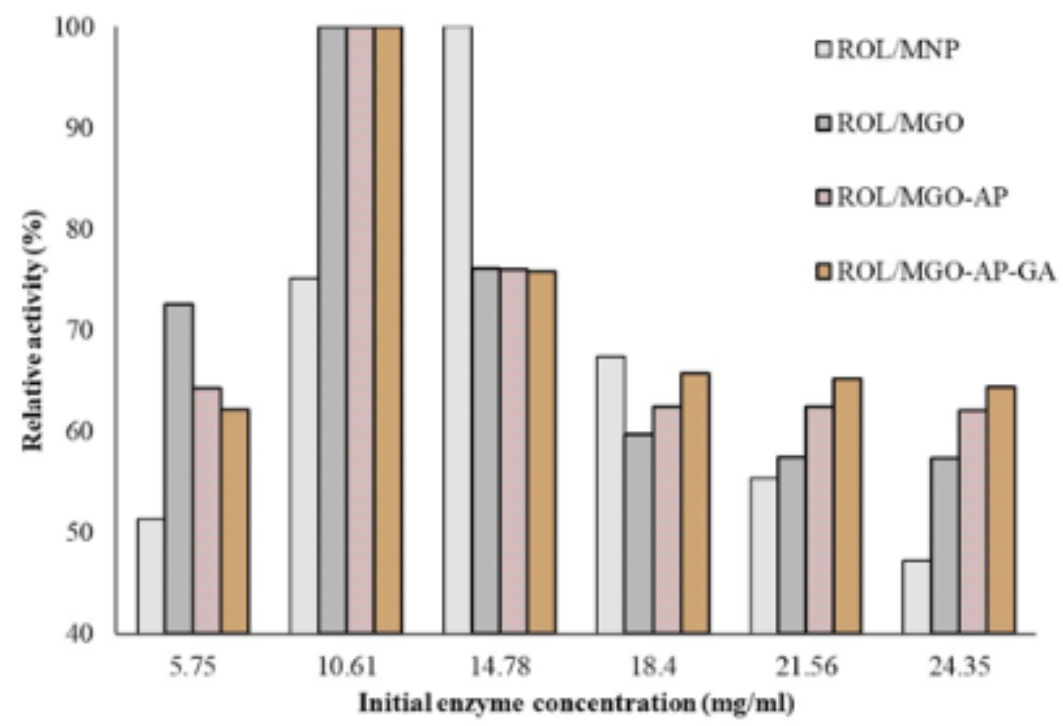

\section{Figure 10}

The effect of ROL initial concentration on the relative activity of nano-biocatalysts.

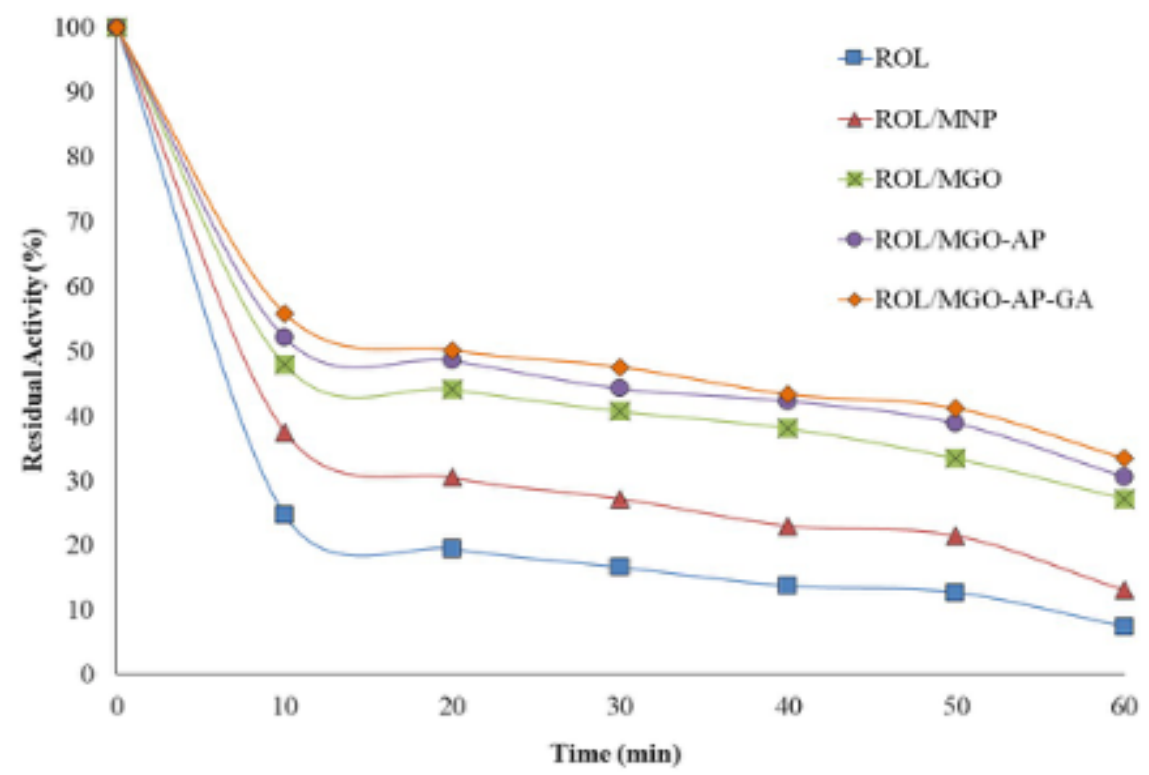

\section{Figure 11}

The time-course thermal stability of free and immobilized ROL. 

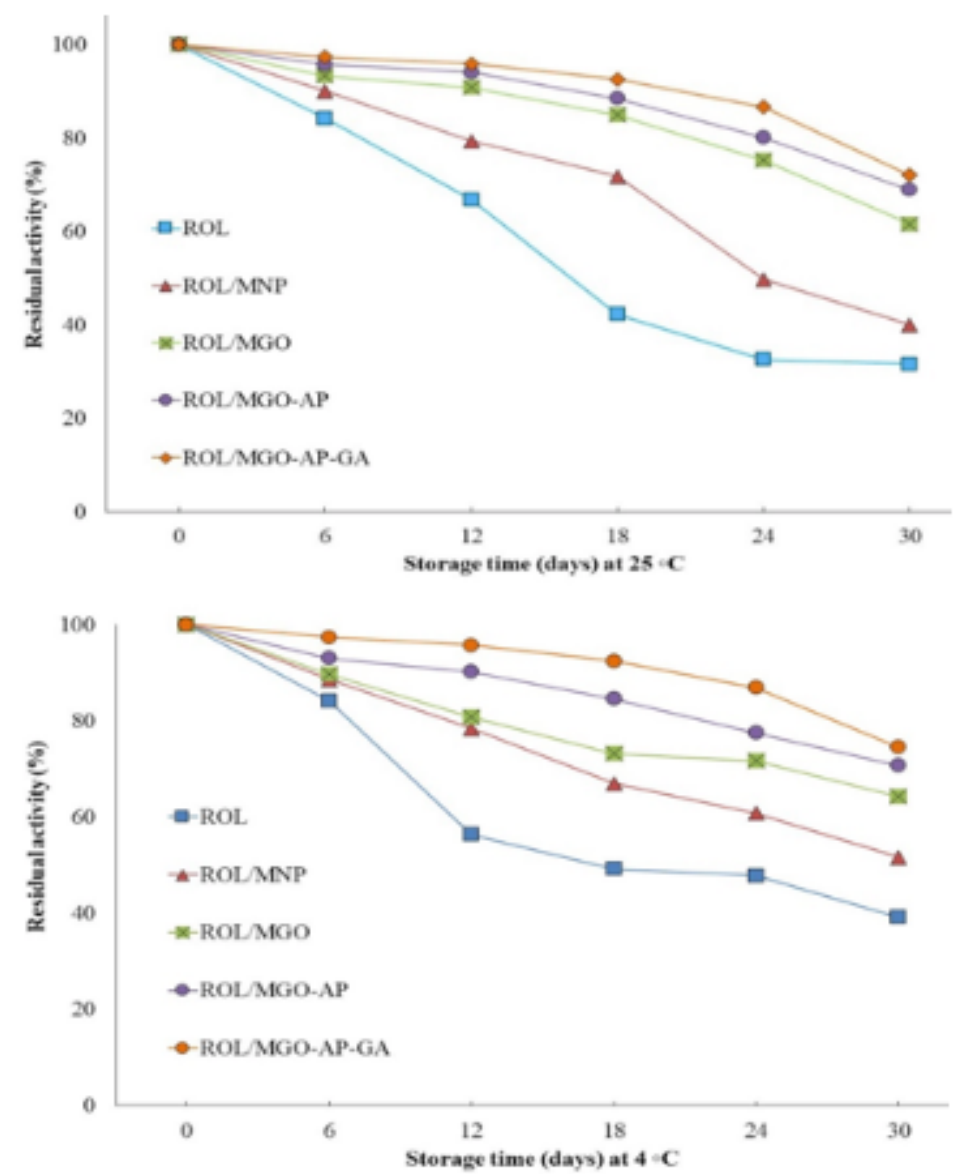

Figure 12

The storage stability of free and immobilized ROL at $25 \circ \mathrm{C}$ and $4 \circ \mathrm{C}$.

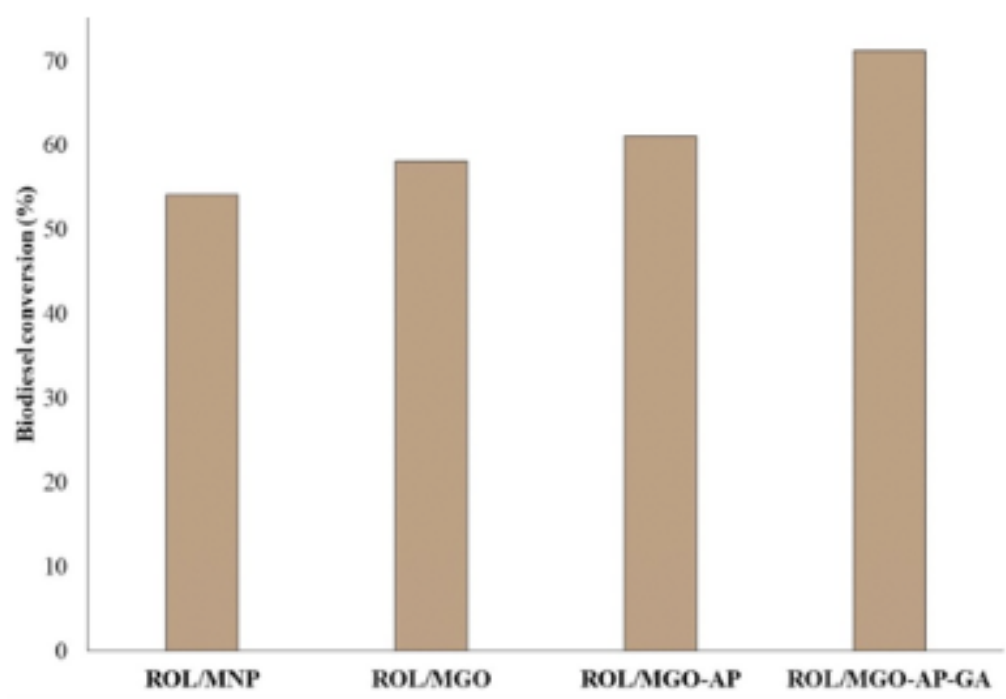

Figure 13

The biodiesel conversion in the presence of free and immobilized ROL. 


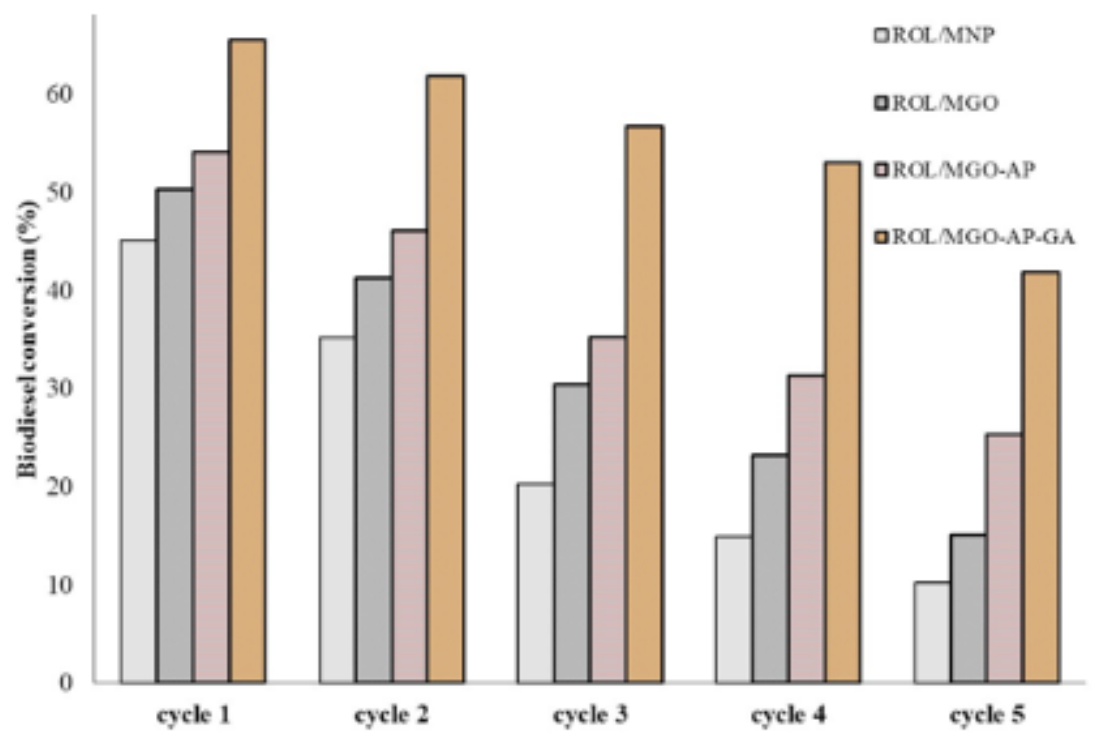

Figure 14

The reusability of ROL/MNP, ROL/MGO, ROL/MGO-AP, and ROL/MGO-AP-GA. 